\section{Summary}

Eighty-one psychotic ("endogenous") depressions were studied to determine the mode of onset of the symptoms, using a graphic method. Four patterns emerged from this investigation: (1) sudden onset (11); (2) gradual onset (50); (3) neurotic onset (14); and (4) fluctuating onset (6).

Groups 1,2, and 3 were examined further to see if other differences could be found. The results seemed to indicate that group 1 (sudden onset) comprised illnesses that were separate and distinct from those of groups 2 and 3, corresponded to the depressed phase of manic-depressive psychosis, and were truly endogenous; while the depressions of groups 2 and 3 were mainly exogenous, and, though probably related to each other, showed different responses to antidepressive drugs, group 2 responding more consistently.
A classification of psychotic depressive illnesses, based on the evidence presented, is set out.

I am grateful to Professor D. Curran and to Dr. J. A. Fraser Roberts for encouragement and detailed advice ; to Mr. H. Gwynne Jones for guidance in the application of statistical methods; to the consultants at St. George's Hospital for access to patients under their care ; to Dr. P. W. Richmond and Dr. A. H. Roberts for their co-operation and help; and to Mrs. J. Haigh for drawing the histograms.

\section{REFERENCES}

Kiloh, L. G., Ball, J. R. B., and Garside, R. F. (1962). Brit. med. F., $1,1225$. and Garside, R. F. (1963). Brit. F. Psychiat., 109, 451.

Leonhard, K., Korff, I., and Schulz, H. (1962). Psychiat. et Neurol. (Basel), 143, 416 .

Rennie, T. A. C. (1942). Amer. F. Psychiat., 98, 801.

\title{
Effects of Surgery under General Anaesthesia on the Electrocardiogram in Ischaemic Heart Disease and Hypertension
}

\author{
D. A. CHAMBERLAIN, ${ }^{*}$ M.B., M.R.C.P.; J. EDMONDS-SEAL,* M.B., F.F.A. R.C.S.
}

\section{Brit. med. F., 1964, 2, 784-787}

Modern agents and techniques have made surgery under general anaesthesia comparatively safe, and there are now few contraindications to its use. Nevertheless, there are patients in whom it carries an appreciable risk; the significance of recent myocardial infarction in this respect is well recognized and operative mortality has been shown to be particularly high in the two years following an acute episode (Knapp et al., 1962). Less emphasis has been placed on the dangers in chronic ischaemic heart disease. Etsten and Proger (1955) found, in a large series, a mortality of $2.9 \%$ in asymptomatic patients with electrocardiographic evidence of coronary heart disease, compared with $2 \%$ in those with normal electrocardiograms (E.C.G.s). In a similar study, comparing patients with and without arteriosclerotic heart disease, Nachlas et al. (1961) noted a much greater difference, with mortality figures of $10.5 \%$ and $3.5 \%$ respectively. Driscoll et al. (1961) recorded E.C.G.s in 496 patients before and after surgery. They found marked fresh ischaemic changes post-operatively in $23 \%$ of the 145 patients in the series with chronic coronary heart disease, hypertension, diabetes, or abnormal pre-operative E.C.G.s; similar changes occurred in less than $3 \%$ of the remaining 351 patients without these conditions.

In the present series the changes which occurred postoperatively in the E.C.G.s of patients with ischaemic heart disease and hypertension have been studied. By relating them to the types of surgery and anaesthesia employed, an attempt has been made to identify those factors which are particularly likely to be associated with electrocardiographic deterioration.

\section{Material and Methods}

Conventional 12-lead E.C.G.s were taken pre-operatively in patients with known or suspected ischaemic heart disease, widespread arterial disease, or hypertension which, for the purpose of this study, was defined as a systolic pressure of $200 \mathrm{~mm}$. $\mathrm{Hg}$ and over or a diastolic pressure of $120 \mathrm{~mm}$. $\mathrm{Hg}$ and over on

- From the Department of Cardiology and the Department of Anaesthesia, St. Bartholomew's Hospital, London. routine ward sphygmomanometry. Arrangements were made before surgery for a tracing to be taken the day after operation from those with definite ischaemic heart disease and from those who were hypertensive by the criteria above. Where the postoperative E.C.G. was markedly changed compared with the previous one, further tracings were usually taken three days later. There were 217 sets of tracings available for analysis; of these, all but 12 were judged to be ischaemic, or had ST and $T$ changes of left ventricular strain.

Patients undergoing thoracic surgery were not accepted into the series. Those with left bundle-branch block were excluded because of the difficulty in detecting fresh ischaemia from their tracings, as were patients in whom surgical dressings made a conventional 12-lead E.C.G. impossible.

Information was obtained from the patients' notes and anaesthetic record cards on the types of operations, the anaesthetic methods and agents used, and in most cases on the bloodpressure measurements throughout surgery.

The pre-operative and post-operative E.C.G.s were reported in pairs without knowledge of the order in which they were taken, and any changes were noted. For simplicity, the changes were classified in the following manner: grade 0 , no change ; grade 1 , slight changes of a type and a degree which are commonly seen in day-to-day variations in patients with ischaemic heart disease ; grade 2, marked changes in ST segments or T waves, or the development of bundle-branch block; grade 3 , changes in $T$ waves of a degree sufficient to suggest fresh infarction.

There were a few E.C.G.s which were very abnormal before and after surgery, causing difficulty in assessing the significance of $\mathrm{T}$-wave changes. However, the reporting of most pairs of tracings presented no great problem.

\section{Results}

Of the 217 sets of E.C.G.s analysed (Table I), 48 (22\%) developed significant electrocardiographic deterioration post- 
operatively. Forty-five of these showed grade 2 changes (Fig. 1). Three patients had post-operative E.C.G.s which indicated probable fresh infarction; in two there was widespread deep symmetrical $T$-wave inversion of a type known to be associated with subendocardial infarction (Pruitt et al., 1955 ; Garcia-Palmieri et al., 1956) (Fig. 2), and in the other

TABLE I.-Changes Which Occurred in 217 Post-operative E.C.G.s Compared with Tracings Taken Before Surgery

\begin{tabular}{|c|c|c|c|c|c|c|c|}
\hline & & \multicolumn{3}{|c|}{ Deteriorated } & \multirow{2}{*}{$\begin{array}{c}\text { No } \\
\text { Change }\end{array}$} & \multicolumn{2}{|c|}{ Improved } \\
\hline & & Grade 3 & Grade 2 & Grade 1 & & Grade 1 & Grade 2 \\
\hline No. of patients & .. & 3 & 45 & 48 & 93 & 23 & 5 \\
\hline Per cent. & .. & 1.5 & 21 & 22 & 43 & $10 \cdot 5$ & 2 \\
\hline
\end{tabular}

$22 \cdot 3 \cdot 63$
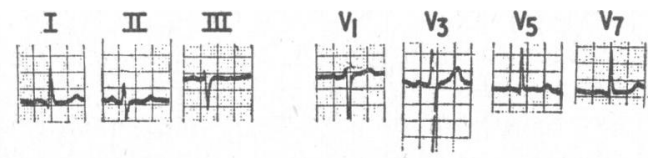

OPERATION

$29 \cdot 3 \cdot 63$
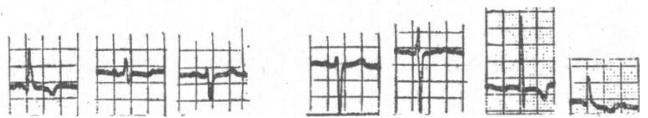

Fig. 1.-An example of a grade-2 change. There were marked $S T$ and $T$ changes post-operatively in standard leads, and $V_{3}$ to $V_{r}$.

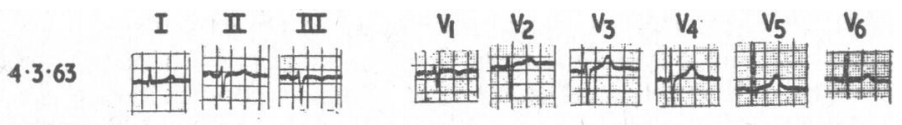
OPERATION

8.3 .63
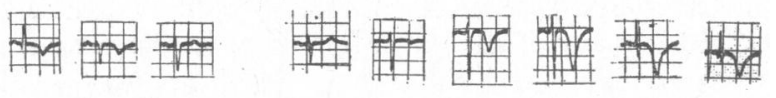

$18 \cdot 3 \cdot 63$
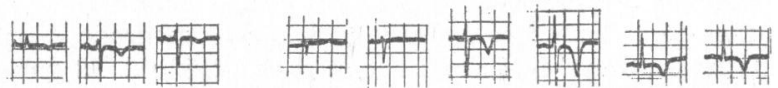

FIG. 2.-An example of a grade-3 change. There was deep T-wave inversion in precordial leads and also $T$-wave changes in standard leads post-operatively. There was little improvement in tracings taken in the following 10 days.

there were marked ST and $\mathrm{T}$ changes with small $\mathrm{Q}$ waves in the mid-precordial leads. None of the three patients complained of chest pain post-operatively, and the electrocardiographic changes provided the only evidence of myocardial damage. In addition, there were two patients in the series in whom further tracings were taken within a week of surgery because of chest pain. Both had unequivocal electrocardiographic evidence of transmural anterior infarction, and both subsequently died: on the basis of their first post-operative E.C.G. these patients who died were classified as showing no change. However, the overall incidence of known or suspected infarction under anaesthesia and in the early post-operative period was in fact $5(2.3 \%)$ out of 217 .

Minor changes (grade 1) were noted in 71 E.C.G.s ; of these, 48 showed slight worsening and 23 slight improvement. There were also five tracings which showed apparent marked improvement (grade 2) ; in three of these the pre-operative pattern was very abnormal, and there was reasonable doubt whether the $T$-wave changes represented improvement or deterioration. The significance of the five showing major improvement must be weighed against that of the 45 patients who showed worsening of similar degree the day after surgery.

There were 106 males and 111 females in the series. Little difference was noted between the sexes in the numbers showing significant (grades 2 and 3) electrocardiographic deterioration: the figures were $25 \%$ for the males and $20 \%$ for the females. Age did not appear to be an important factor in determining risk. The majority of patients fell in the age-group 50 to 79 years. A broad division of ages at 60 years showed $23 \%$ deterioration below 60 , and $21 \%$ at 60 years and above.
Ninety-three patients were classified as hypertensive by the criteria given above, leaving 124 non-hypertensive patients. In the former group $23 \%$ showed significant deterioration and in the latter $21 \%$.

The types of surgery performed on the patients in this series were varied, and ranged from minor investigations to major surgery, but all were under general anaesthesia. Eighty-nine had abdominal operations and 128 had non-abdominal surgery. The incidence of marked electrocardiographic deterioration was $28 \%$ in the abdominal group, compared with $18 \%$ in the nonabdominal group. This difference became somewhat more impressive when the division was made between the 54 patients who had the peritoneal cavity opened and the 163 who did not; the incidences of deterioration were then $33 \%$ against $18 \%$. The duration of surgery (Table II) may also have been import-

TABLE II.-Changes Which Occurred in the Post-operative E.C.G.s of 169 Patients for Whom the Duration of Surgery was Accurately Known

\begin{tabular}{|c|c|c|c|c|c|c|c|c|c|c|c|c|c|}
\hline \multirow{3}{*}{\multicolumn{2}{|c|}{ Duration of surgery: }} & \multicolumn{4}{|c|}{ Less than 1 hour } & \multicolumn{4}{|c|}{1 to 2 hours } & \multicolumn{4}{|c|}{ More than 2 hours } \\
\hline & & \multicolumn{2}{|c|}{$\begin{array}{c}\text { Deterior- } \\
\text { ated }\end{array}$} & \multirow[b]{2}{*}{ 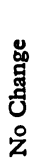 } & \multirow[b]{2}{*}{ 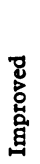 } & \multicolumn{2}{|c|}{$\begin{array}{c}\text { Deterior- } \\
\text { ated }\end{array}$} & \multirow[b]{2}{*}{ 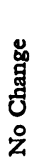 } & \multirow[b]{2}{*}{ 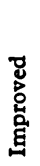 } & \multicolumn{2}{|c|}{$\begin{array}{c}\text { Deterior- } \\
\text { ated }\end{array}$} & \multirow{2}{*}{ 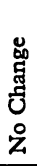 } & \multirow[b]{2}{*}{ 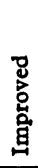 } \\
\hline & & 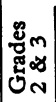 & $\overrightarrow{\tilde{g}}$ & & & 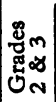 & 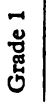 & & & $\begin{array}{l}\mathscr{B}_{m} \\
\mathbb{Z}_{\infty} \\
\mathcal{J}_{N}\end{array}$ & 苟 & & \\
\hline No. of patients & .. & 8 & 12 & 25 & 8 & 17 & 18 & 41 & 11 & 10 & 11 & 4 & 4 \\
\hline Per cent. .. & .. & 15 & 23 & 47 & 15 & 20 & 21 & 47 & 13 & 34 & 38 & 14 & 14 \\
\hline
\end{tabular}

ant ; 10 (34\%) of the 29 patients who were known to have had operations lasting over two hours had grade 2 or grade 3 electrocardiographic deterioration.

Adequate blood-pressure records during surgery were available in 155 cases. An analysis of the effect of the extent of blood-pressure fall is presented in Table III. In 45 patients

TABLE III.-Changes Which Occurred in the Post-operative E.C.G.s of 155 Patients for Whom the Extent of the Fall in Systolic Bloodpressure Under Anaesthesia was Known

\begin{tabular}{|c|c|c|c|c|c|c|c|c|c|c|c|c|c|}
\hline & & \multicolumn{12}{|c|}{ Fall in Systolic Pressure under Anaesthesia } \\
\hline & & \multicolumn{4}{|c|}{$\begin{array}{c}\text { Less than } 50 \\
\mathrm{~mm} . \mathrm{Hg}\end{array}$} & \multicolumn{4}{|c|}{50 to $99 \mathrm{~mm} . \mathrm{Hg}$} & \multicolumn{4}{|c|}{$100 \underset{\text { over }}{\mathrm{mm}} \mathrm{Hg}$ or } \\
\hline & & \multicolumn{2}{|c|}{$\begin{array}{c}\text { Deterior- } \\
\text { ated }\end{array}$} & \multirow{2}{*}{ 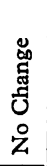 } & \multirow[b]{2}{*}{ 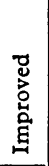 } & \multicolumn{2}{|c|}{$\begin{array}{c}\text { Deterior- } \\
\text { ated }\end{array}$} & \multirow{2}{*}{ 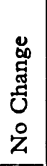 } & \multirow[b]{2}{*}{ 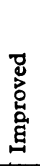 } & \multicolumn{2}{|c|}{$\begin{array}{c}\text { Deterior- } \\
\text { ated }\end{array}$} & \multirow{2}{*}{ 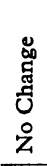 } & \multirow[b]{2}{*}{ 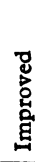 } \\
\hline & & $\begin{array}{l}\mathscr{S}_{m} \\
\mathbb{J}_{\infty} \\
\mathcal{J}_{N}\end{array}$ & 总 & & & $\begin{array}{l}\mathbb{J}_{n} \\
\mathbb{\pi}_{\infty} \\
\mathcal{U}_{N}\end{array}$ & 莺 & & & 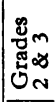 & $\begin{array}{l}\overrightarrow{0} \\
\text { ర్ల } \\
0\end{array}$ & & \\
\hline No. of patients & $\cdots$ & 6 & 10 & 19 & 10 & 13 & 16 & 32 & 7 & 10 & 14 & 15 & 3 \\
\hline Per cent. .. & $\ldots$ & 13 & 22 & 42 & 22 & 19 & 23 & 47 & 10 & 24 & 33 & 36 & 7 \\
\hline
\end{tabular}

the maximum fall in systolic pressure during anaesthesia, compared with the pre-operative figure, was less than $50 \mathrm{~mm} . \mathrm{Hg}$; 68 patients had a fall of 50 to $99 \mathrm{~mm}$. $\mathrm{Hg}$; and 42 patients had falls of $100 \mathrm{~mm}$. or over. In these groups the proportions showing major electrocardiographic deterioration were $13 \%$, $19 \%$, and $24 \%$ respectively. Duration of blood-pressure fall was also considered, accepting a minimum drop of $50 \mathrm{~mm}$. $\mathrm{Hg}$ as a "fall" (Table IV). Of those in whom it lasted less than 15 minutes, $4 \%$ deteriorated, compared with $20 \%$ with falls of 15 to 60 minutes' duration, and $32 \%$ with falls of over 60 minutes' duration.

Eighteen anaesthetists were concerned with the patients in this study, and although in many cases similar drugs or combinations of drugs were used, many different methods of anaesthesia were employed. This made classification of the types of anaesthesia cumbersome and somewhat complicated, so broad divisions were made in an effort to compare the results of different drugs and procedures. Premedication had no apparent influence on post-operative electrocardiographic changes. One hundred and twelve patients were intubated and 105 were not. There was little difference in the incidence 
of deterioration in each group. Similarly, the use of halothane and of trichlorethylene could not be related to post-operative electrocardiographic deterioration. It appeared on the first analysis that intermittent-positive-pressure respiration and long-acting relaxants were associated with an increased incidence of electrocardiographic change. However, both were itivariably used in the operations involving peritoneal incision, and this accounted for the excess showing deterioration in ihese groups. No increased risk was apparent in the other cases in which intermittent-positive-pressure respiration and long-acting relaxants were used. Post-operatively there was no increase in the number of patients in atrial fibrillation, and ao other fresh arrhythmias were noted.

TABLB IV.-Changes Which Occurred in the Post-operative E.C.G.s Related to the Duration of Fall in Blood-pressure in 111 Patients. $A$ "Fall" in Blood-pressure was Defined as a Lowering of Systolic Pressure of $50 \mathrm{~mm} . \mathrm{Hg}$ or More

\begin{tabular}{|c|c|c|c|c|c|c|c|c|c|c|c|c|c|}
\hline & & \multicolumn{12}{|c|}{$\begin{array}{c}\text { Duration of Fall in Systolic Blood Pressure under } \\
\text { Anaesthesia }\end{array}$} \\
\hline & & \multicolumn{4}{|c|}{ Less than 15 mins. } & \multicolumn{4}{|c|}{15 to 60 mins. } & \multicolumn{4}{|c|}{$\begin{array}{c}\text { More than } 60 \\
\text { mins. }\end{array}$} \\
\hline & & \multicolumn{2}{|c|}{$\begin{array}{c}\text { Deterior- } \\
\text { ated }\end{array}$} & \multirow{2}{*}{ 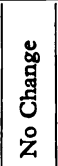 } & \multirow[b]{2}{*}{ 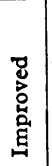 } & \multicolumn{2}{|c|}{$\begin{array}{c}\text { Deterior- } \\
\text { ated }\end{array}$} & \multirow{2}{*}{ 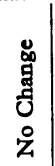 } & \multirow[b]{2}{*}{$\begin{array}{l}\text { 总 } \\
\text { 总 } \\
\text { 宫 }\end{array}$} & \multicolumn{2}{|c|}{$\begin{array}{c}\text { Deterior- } \\
\text { ated }\end{array}$} & \multirow[b]{2}{*}{$\mid \begin{array}{l}: \\
0 \\
0 \\
0 \\
0 \\
0 \\
\circ \\
z\end{array}$} & \multirow[b]{2}{*}{$\begin{array}{l}\text { 总 } \\
\text { 莒 } \\
\text { 宣 }\end{array}$} \\
\hline & & 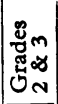 & $\mid \begin{array}{l}\overrightarrow{\tilde{g}} \\
\tilde{u} \\
\tilde{s}\end{array}$ & & & 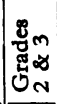 & $\begin{array}{l}\vec{u} \\
\tilde{g} \\
\tilde{J}\end{array}$ & & & 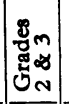 & $\overrightarrow{\tilde{g}}$ & & \\
\hline No of patients & .. & $\overline{1}$ & $\overline{6}$ & 14 & 4 & 12 & 16 & 23 & 4 & 10 & 9 & 10 & 2 \\
\hline Per cent. .. & $\ldots$ & $\overline{4}$ & 24 & 56 & 16 & 20 & $\overrightarrow{29}$ & 42 & 7 & 32 & 29 & 32 & 7 \\
\hline
\end{tabular}

\section{Discussion}

Many of the variable factors during surgery and anaesthesia have been under consideration to find any which were particularly associated with adverse electrocardiographic changes and therefore carried a special risk. The three which appeared to be important were large or prolonged blood-pressure falls, a duration of surgery over two hours, and abdominal surgery. Increased risk was associated with each of these factors even when due allowance was made for the other two. As would be expected, the patients with the greatest blood-pressure falls also tended to have falls for a longer time, and it was impossible to separate these groups. It is not surprising that a fall in blood-pressure should be an unfavourable factor: agents which reduce the systemic pressure may often depress cardiac output, and coronary filling pressure will certainly be lowered. Accepting that there is any risk of fresh myocardial ischaemia with surgery under general anaesthesia, it could be predicted that duration of surgery would prove important. Other series have shown an increased mortality in patients with heart disease after operations lasting longer than two hours, and the present findings are in accord with these (Hannigan et al., 1951; Jacobson and Beaconsfield, 1958 ; Nachlas et al., 1961).

The significance of the increased risk with abdominal surgery is less obvious. Post-operative hypoxia may be more severe in these cases than it is in patients having non-abdominal surgery. There was a further increase in risk in the group in whom the peritoneum was incised. Rocco and Vandam (1957) made observations on 526 patients during laparotomy, of whom 175 had noticeable falls in blood-pressure associated with rubbing of the parietal peritoneum, traction on the stomach or gall-bladder or mesentery, or pressure on the coeliac plexus. $\mathrm{T}$-wave inversion or ST depression occurred in 25 of these patients. Later Vandam et al. (1962) made further studies of this phenomenon, and found the fall in pressure to be due to a lowered cardiac output, which they thought was reflex but not mediated by the vagus.

The increased risk in the " peritoneal" patients in the present series did not correlate well with falls in blood-pressure, although transient falls may have occurred and not been observed. Mendelsohn and Monheit (1956) studied 50 patients undergoing biliary tract and upper abdominal surgery, 30 of whom had coronary disease. Of these 30, four had E.C.G.s which were improved post-operatively, but in nine the tracings showed increased ischaemia and four had changes consistent with the development of myocardial infarction; significant hypotension occurred during surgery in only two of these patients. Gilbert et al. (1940a) found that raising the intragastric pressure of dogs to $15 \mathrm{~mm}$. $\mathrm{Hg}$ usually reduced coronary blood-flow reflexly irrespective of blood-pressure changes, and the same workers (Gilbert et al., 1940b) adduced evidence that similar reflexes exist in man. There is thus a possibility, at least, that reflex coronary vasoconstriction is a cause of increased myocardial ischaemia during surgery involving handling of the peritoneum and associated viscera.

In addition to the marked grade 2 and grade 3 changes, there were 48 patients who showed minor (grade 1) deterioration post-operatively, compared with 23 with minor improvement. If surgery and anaesthesia did not influence these minor variations one would have expected similar numbers to improve and deteriorate. While these changes were not pathognomonic of fresh myocardial ischaemia, great care was taken to exclude differences due to variations in the electrical position of the heart and the position of the electrodes, and also changes due to the effects of tachycardia. It is of interest that Driscoll et al. (1961) found minor electrocardiographic changes postoperatively nearly six times more often in patients with known or suspected coronary disease than in patients with no clinical evidence of myocardial ischaemia. This is good evidence that most of the changes in his series were due, at least in part, to fresh myocardial ischaemia, and it is likely that the same is true for many of the minor variations in the present series.

It proved impossible to take follow-up tracings in all the patients in the series. Further post-operative E.C.G.s were therefore limited to those who had shown grade 2 or grade 3 deterioration: they were obtained in 32 of the 48 patients, and taken four days after surgery. The fresh ischaemic changes had resolved in only 13 of the 32 , with improvement in some of the others. Thus the majority were more than fleeting alterations in pattern, and represented muscle injury or, in a few cases, muscle death. This was in patients who already had heart disease with some limitation of cardiac reserve, and who were least able to afford further myocardial damage. It is clear that surgery under general anaesthesia carries an appreciable risk of electrocardiographic deterioration in patients with ischaemic heart disease and severe hypertension, and this risk should be considered when planning their surgical treatment.

\section{Summary}

Electrocardiograms were taken before surgery under general anaesthesia and repeated within 24 hours afterwards in 217 patients with ischaemic heart disease or severe hypertension. In 96 patients there was electrocardiographic deterioration, and this was marked in 48 of them. Three had changes suggestive of infarction; two others, in whom the first post-operative E.C.G. showed no fresh ischaemia, developed unequivocal clinical and electrocardiographic evidence of infarction within a week of surgery. There was some correlation between the risk of electrocardiographic deterioration and the fall in bloodpressure during anaesthesia, the duration of surgery, and abdominal operations. The implications of these findings are discussed.

Part of this work was done while one of us (D. A. C.) was in receipt of an Aylwen Research Bursary. We are grateful to Dr. G. W. Hayward, Mr. Frankis T. Evans, and Dr. T. B. Boulton for advice and encouragement; to the surgeons of the hospital for permission to study patients under their care; to the anaesthetists and house-surgeons for their co-operation; and to the 
technicians of the department of cardiology for their help with the electrocardiograms.

\section{REFERENCES}

Driscoll, A. C., Hobika, J. H., Etsten, B. E., and Proger, S. (1961). New Engl. 7. Med., 264, 633 .

Etsten, B., and Proger, S. (1955). 7. Amer. med. Ass., 159, 845.

Garcia-Palmieri, M. R., Marchand, E. J., Diaz-Rivera, R. S., SantiagoStevenson, D., and Rodriguez, H. F. (1956). Amer. Heart 7., 52, 521.

Gilbert, N. C., LeRoy, G. V., and Fenn, G. K. (1940a). Ibid., 20, 519. Fenn, G. K., and LeRoy, G. V. (1940b). ł. Amer. med. Ass., 115,
Hannigan, C. A., Wroblewski, F., Lewis, W. H., and LaDue, J. S. (1951). Amer. ¥. med. Sci., 222, 6238 .

Jacobson, H. A., and Beaconsfield, P. (1958). F. Amer. geriat. Soc., 6, 657.

Knapp, R. B., Topkins, M. J., and Artusio, J. F. (1962). F. Amer. med. Ass., 182, 332.

Mendelsohn, D., and Monheit, R. (1956). New Engl. 7. Med., 254, 307. Nachlas, M. M., Abrams, S. J., and Golberg, M. M. (1961), Amer. ;. Surg., 101, 447.

Pruitt, R.'D., Klakeg, C. H., and Chapin, L. E. (1955). Circulation, 11, 517.

Rocco, A. G., and Vandam, L. D. (1957). F. Amer. med. Ass., $164,14$. Vandam, L. D., Schweizer, H. J., and Kubota, Y. (1962). Circulat. Res.,

\title{
"Giant Follicle Lymphoma of the Spleen"
}

\section{A Condition Closely Related to Lymphatic Leukaemia but Apparently Curable by Splenectomy}

\author{
R. A. HICKLING, * B.A., M.D., F.R.C.P.
}

[With Special Plate]

Brit. med.f., 1964, 2, 787-790

In 1960, under the title " Giant Follicle Lymphoma of the Spleen" (Hickling, 1960), a description was given of four patients with the following features: (1) Massive splenomegaly without enlargement of superficial lymph nodes. (2) Lymphocytosis without any great increase in total leucocytes, and with the presence of abnormal and immature mononuclear cells in the circulating blood. (3) Large numbers of lymphocytes in bone-marrow aspiration films. (4) In the two cases in which bone-marrow biopsy was carried out there were numbers of lymphocyte foci in active marrow. (5) Excellent clinical result of splenectomy. (6) In the course of time the abnormal and immature mononuclear cells in the circulating blood disappeared and the leucocyte count returned to normal, the lymphocytosis disappearing. (7) In the three cases in which liver biopsy was carried out at the time of splenectomy there were abnormal lymphocyte accumulations in the portal tracts. (8) No superficial lymph-node enlargements occurred during the periods of observation, and the patients remained well.

The object of this paper is to examine the relation of the four cases previously described, and a fifth case seen since that paper was written, to chronic lymphatic leukaemia. Summaries were given of the first four cases in the paper already referred to, but brief summaries are given here of these four cases and a longer report of the fifth case, hitherto undescribed.

\section{Case 1}

A woman aged 34 when first seen in September 1952 complained of lack of energy for 18 months and increasing abdominal swelling for two months. Splenomegaly was present, there was no anaemia, and the leucocytes in the circulating blood varied between 10,000 and $15,000 /$ c.mm., of which 75 to $80 \%$ were lymphocytes, with 2 to $9 \%$ of immature and abnormal forms. Sternal puncture in 1952 and 1953 showed a predominantly lymphatic bone-marrow. $X$-ray therapy of the spleen and, later, a course of nitrogen mustard intravenously caused a very temporary effect only on the size of the spleen and on the general health, and produced transient

* Physician, Charing Cross Hospital, London. leucopenia. Splenectomy in February 1954 produced an excellent clinical response. By February 1955, one year after splenectomy, the total and differential leucocyte counts in the circulating blood were normal, and no abnormal cells were seen.

The histology of the spleen was that of giant follicle lymphoma. Many enlarged lymphatic glands were found in the abdomen, but these were not removed, except those which came away with the spleen and which showed similar changes to that of the spleen. Liver biopsy showed accumulations of lymphocytes in the portal tracts. The patient remained well $10 \frac{1}{2}$ years after splenectomy, the circulating blood remained normal, and no enlargement of lymph nodes had occurred. No histological examination of the bone-marrow was made in this case.

\section{Case 2}

In April 1956 a woman, then aged 43, was first seen on account of thrombosis of the central artery of the retina in the left eye. For four months she had had abnormal tiredness, colicky abdominal pains, and diarrhoea with a feeling of pressure in the abdomen. Splenomegaly and a mild anaemia were present, the leucocyte counts were about 5,000/c.mm., of which over $60 \%$ were lymphocytes, with about $4 \%$ of abnormal and immature forms. Sternal-marrow-puncture films revealed large numbers of lymphocytes. Bone-marrow biopsy showed the presence of lymphocyte foci in an active bone-marrow (Special Plate, Fig. 1). Three separate courses of $x$-ray treatment of the spleen caused some decrease in size of the organ and some improvement in general health, but these were transitory.

Splenectomy in April 1959 produced an excellent clinical result. At operation another bone-marrow biopsy again showed numbers of lymphocyte foci in an active bone-marrow, liver biopsy showed lymphatic accumulations in the portal tracts (Special Plate, Fig. 2), and the histology of the lymph nodes in the hilum of the spleen and the histology of the spleen itself (Special Plate, Fig. 3) were more like those of giant follicle lymphoma than of lymphatic leukaemia. Large numbers of lymph nodes were present in the abdomen, but no attempt was made to remove them. The circulating blood gradually became normal, but by August 1959 a few abnormal and immature mononuclear cells were still present in the circulating blood. Five years after splenectomy the patient was well, with a 